\title{
Novos táxons de Desmiphorini (Coleoptera, Cerambycidae) do Equador e Bolívia e redescrição de Estola medionigra Breuning
}

\author{
Ubirajara R. Martins ${ }^{1,3}$ \& Maria Helena M. Galileo ${ }^{2,3}$
}

${ }^{1}$ Museu de Zoologia, Universidade de São Paulo, Caixa Postal 42494, 04218-970 São Paulo-SP, Brasil.

${ }^{2}$ Museu de Ciências Naturais, Fundação Zoobotânica do Rio Grande do Sul, Caixa Postal 1188, 90001-970 Porto Alegre-RS, Brasil.

${ }^{3}$ Bolsista do CNPq.

\begin{abstract}
New taxa of Desmiphorini (Coleoptera, Cerambycidae, Lamiinae) from Ecuador and Bolívia and redescription of Estola medionigra Breuning. New taxa are described: from Ecuador, Cotyschnolea gen. nov., type species, Cotyschnolea minuta sp. nov. (Loja); Mimasyngenes murutinga sp. nov. (Manabi); Stereomerus hovorei sp. nov. (Manabi) and from Bolivia, Estola timbauba sp. nov. (Santa Cruz); Inermestoloides rumuara sp. nov. (Santa Cruz). Estola medionigra Breuning, 1940 is redescribed and a new record for Guiana Francesa is given.
\end{abstract}

KEYWORDS. Desmiphorini; Lamiinae; Neotropica; Taxonomy.

RESUMO. Novos táxons de Desmiphorini (Coleoptera, Cerambycidae) do Equador e Bolívia e redescrição de Estola medionigra Breuning. Novos táxons são descritos: do Equador, Cotyschnolea gen. nov., espécie-tipo, Cotyschnolea minuta sp. nov. (Loja); Mimasyngenes murutinga sp. nov. (Manabi); Stereomerus hovorei sp. nov. (Manabi) e da Bolívia, Estola timbauba sp. nov. (Santa Cruz); Inermestoloides mocoia sp. nov. (Santa Cruz). Estola medionigra Breuning, 1940 é redescrita e registrada pela primeira vez na Guiana Francesa.

PALAVRAS-CHAVE. Desmiphorini; Lamiinae; Neotropica; Taxonomia.

Após a revisão da tribo Desmiphorini por Breuning (1974), muitos táxons têm sido descritos (Monné, 2005). Os gêneros podem ser agrupados pelos lados do protórax com espinho ou desarmados. Para este último grupo, Martins \& Galileo (1998) apresentaram chave para os gêneros e diagnosticaram Inermestoloides Breuning, 1966 pelo escapo sem cicatriz, antenômero III mais curto que o escapo e que o antenômero IV e pronoto sem tubérculos. Os gêneros Estola Fairmaire \& Germain, 1859, Mimasyngenes Breuning, 1950, Stereomerus Melzer, 1934 apresentam espinho nos lados do protórax. Martins \& Galileo (1994) e Galileo \& Martins (1996) revisaram, respectivamente, Stereomerus e Mimasyngenes. O gênero Estola é amplo e reúne 89 espécies (Monné, 2005). Objetiva-se acrescentar novas espécies a esses gêneros e um novo gênero à tribo.

O material foi recebido para estudo da Coleção Roy Morris, Lakeland, Florida, Estados Unidos (CRML), Frank T. Hovore Collection, Santa Clarita, Califórnia, Estados Unidos (FTHC), Florida State Collection of Arthropods, Gainesville, Florida, Estados Unidos (FSCA), Muséum National d'Histoire Naturelle, Paris, França (MNHN). Com autorização dos responsáveis, parte do material está sendo depositado no Museo de Historia Natural Noel Kempff Mercado, Santa Cruz, Bolívia (MNKM), Museu de Ciências Naturais, Fundação Zoobotânica do Rio Grande do Sul, Porto Alegre, Brasil (MCNZ) e Museu de Zoologia, Universidade de São Paulo, São Paulo, Brasil (MZSP).

\section{Cotyschnolea gen. nov.}

Espécie-tipo, Cotyschnolea minuta sp. nov.

Fronte subquadrangular. Região entre os tubérculos anteníferos apenas deprimida. Olhos com omatídios de diâmetro médio; lobos oculares inferiores pouco mais curtos que a área malar. Escapo cilíndrico, sem cicatriz apical. Antenas com 11 artículos, antenômero III subigual em comprimento ao escapo e um terço mais curto que o IV.

Protórax tão longo quanto largo, arredondado nos lados. Pronoto sem tubérculos látero-anteriores, mas acentuadamente elevado no meio do disco. Processo mesosternal sem tubérculo e truncado na parte anterior.

Élitros com setas eretas; cada élitro com um tubérculo pósbasal, arredondado no topo; extremidades elitrais arredondadas.

Cavidades coxais intermediárias abertas. Fêmures com pedúnculo curto. Fêmures e tíbias com setas longas. Mesotíbias com sulco no terço apical.

Discussão. Alguns gêneros de Desmiphorini apresentam tubérculo no dorso da base dos élitros como, por exemplo, Diliolophus Bates 1885, procedente da Guatemala e Gibbestoloides Breuning, 1940, que ocorre no Brasil (Bahia)e na Argentina (Chaco). Cotyschnolea gen. nov. distingue-se de ambos por apresentar o corpo e os apêndices providos de setas longas. 
Pela chave para os gêneros sul-americanos de Desmiphorini com lados do protórax desarmados (Martins \& Galileo, 1998), Cotyschnolea gen. nov. é discriminado no item 6(5) junto com Parischnolea Breuning, 1942 e Ceiupaba Martins \& Galileo, 1998. Cotyschnolea gen. nov. difere de Parischnolea pelo pronoto acentuadamente elevado no meio do disco, pelo protórax mais arredondado nos lados, pela presença de tubérculo na base dos élitros e pelas extremidades elitrais arredondadas. Em Parischnolea, o pronoto é regularmente convexo, os lados do protórax são ligeiramente arredondados, a base dos élitros não tem tubérculos e as extremidades elitrais têm espinho externo. Ceiupaba também não apresenta tubérculos no pronoto e na base dos élitros.

Etimologia. Tupi, koty = ao lado de; Ischinolea, nome de gênero de Desmiphorini

\section{Cotyschnolea minuta sp. nov.}

(Fig. 1)

Cabeça revestida por pubescência esbranquiçada e esparsa, mais adensada atrás dos lobos oculares inferiores. Escapo com tegumento castanho; pedicelo e flagelômeros com a base avermelhada, gradualmente mais escuros em direção aos antenômeros apicais; XI inteiramente preto. Pêlos dos flagelômeros mais longos do que o dobro da largura dos artículos.

Protórax com pubescência esbranquiçada; pubescência amarelada em estreita faixa central e numa área atrás da gibosidade central.

Cada élitro com faixa transversal de pubescência alaranjada, da base até o tubérculo pós-basal; faixa larga, de pubescência branca, ante-mediana, oblíqua em sentido descendente da margem para a sutura, muito interrompida por manchas tegumentares escuras; na metade apical, faixa preta, paralela à anterior, ocupa a metade anterior do terço apical e é entremeada por manchas de pubescência alaranjada e branca; faixa de pubescência branca, transversal, irregular no quarto apical; extremidades elitrais com mancha alaranjada circundada por preto, exceto a borda apical que é branca.

Ápices dos fêmures e $2 / 3$ basais das tíbias com tegumento avermelhado. Fêmures e face ventral revestidos por pubescência esbranquiçada.

Dimensões em mm, fêmea. Comprimento total, 3,9-4,8; comprimento do protórax, 1,0-1,2; maior largura do protórax, 1,1-1,3; comprimento do élitro, 2,7-3,4; largura umeral, 1,3-1,6.

Material-tipo. Holótipo fêmea, EQUADOR, Loja: Catamayo, 24.III.2001, F. T. Hovore col. (FTHC). Parátipo fêmea, ditto (18 km SW), 25.III.2001, F. T. Hovore col. (MZSP).

\section{Mimasyngenes murutinga sp. nov.}

(Fig. 2)

Tegumento castanho-avermelhado; todo corpo e apêndices providos de setas longas, esbranquiçadas. Fronte com a largura igual ao dobro do comprimento, revestida por pubescência branca esparsa. Lobos oculares superiores com cinco fileiras de omatídios, tão distantes entre si quanto o dobro da largura de um lobo. Vértice coberto por pubescência esbranquiçada. Escapo com tegumento avermelhado, mais escuro na região apical. Antenômero III apenas mais longo que oIV.

Espinho lateral do protórax longo, acuminado, voltado para trás, localizado no nível do terço posterior. Pronoto com pubescência branca, esparsa no disco e densa nos lados; pontuação pronotal densa e profunda.

Élitros cobertos por pubescência branca exceto áreas glabras: região basal no sexto anterior projetada posteriormente junto à sutura; pequena área longitudinal, dorsal, logo atrás do meio; mancha longitudinal, dorsal, no terço apical. Pontuação grossa na metade anterior, acobertada pela pubescência.

Face ventral e pernas revestidas por pubescência esbranquiçada. Metepisternos pontuados.

Dimensões em mm, holótipo fêmea. Comprimento total, 4,9; comprimento do protórax, 1,1; maior largura do protórax (espinhos inclusive), 1,5; comprimento do élitro, 3,7; largura umeral, 1,7 .

Material-tipo. Holótipo fêmea, EQUADOR, Manabi: Montecristi ("vicinity"), 9-10.III.2003, F. T. Hovore col. (FTHC).

Discussão. Mimasyngenes murutinga sp. nov. difere de $M$. lucianae Galileo \& Martins, 2003 pelo padrão de colorido dos élitros onde a pubescência é predominantemente esbranquiçada com apenas a base e duas manchas glabras. Em M. lucianae, a região circum-escutelar é coberta por pubescência branca e as áreas glabras são uma faixa oblíqua do úmero à sutura e uma grande área atrás do meio dos élitros. Pelo espinho lateral do protórax longo e situado no terço posterior, discriminado na chave para as espécies de Galileo \& Martins (1996), assemelhase a $M$. quiuira Galileo \& Martins, 1996, mas difere pela pubescência elitral que não constitui faixas longitudinais, evidentes em M. quiuira.

Etimologia. Tupi, murutinga = branco; alusivo à pubescência corporal branca.

\section{Stereomerus hovorei sp. nov.}

(Fig. 3)

Tegumento castanho. Cabeça recoberta por pubescência amarelada, densa e longa na fronte e numa faixa atrás dos olhos; toda cabeça pontuada, os pontos são moderados. Fronte retangular. Lobos oculares inferiores com o quádruplo da comprimento das genas; lobos oculares superiores com seis fileiras de omatídios, a distância entre eles igual à metade da largura de um lobo. Tubérculos anteníferos projetados e subcontíguos.

Antenas com tegumento acastanhado, mas amarelado na base dos antenômeros a partir do IV e em áreas gradualmente maiores para o ápice; pêlos evidentes e numerosos ao redor de 


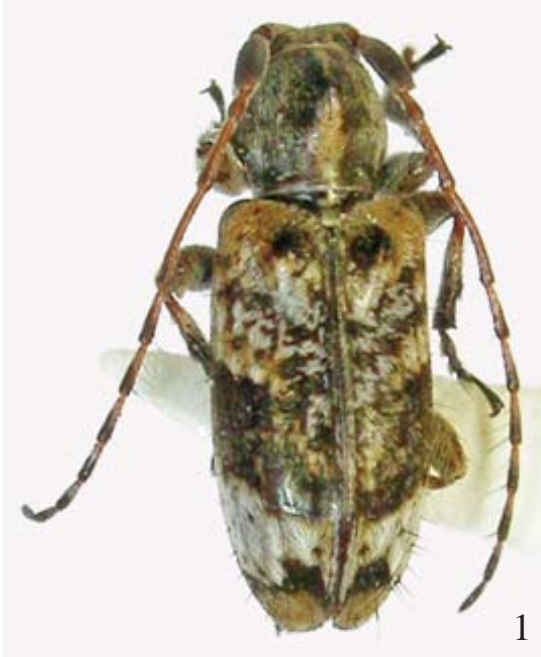

1

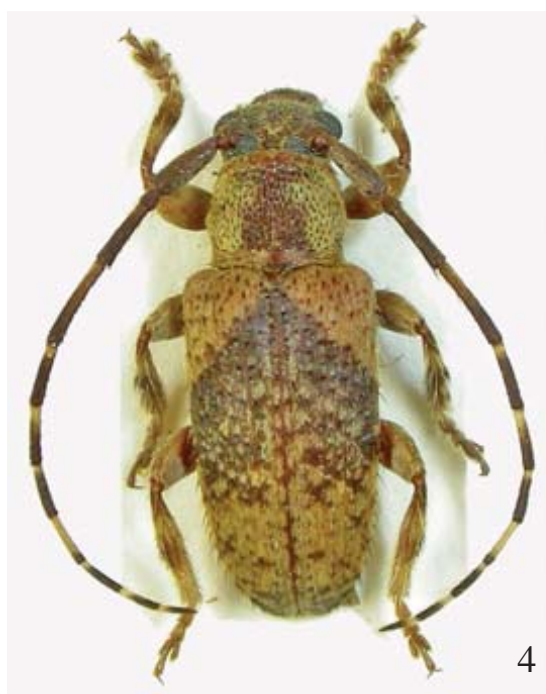

4
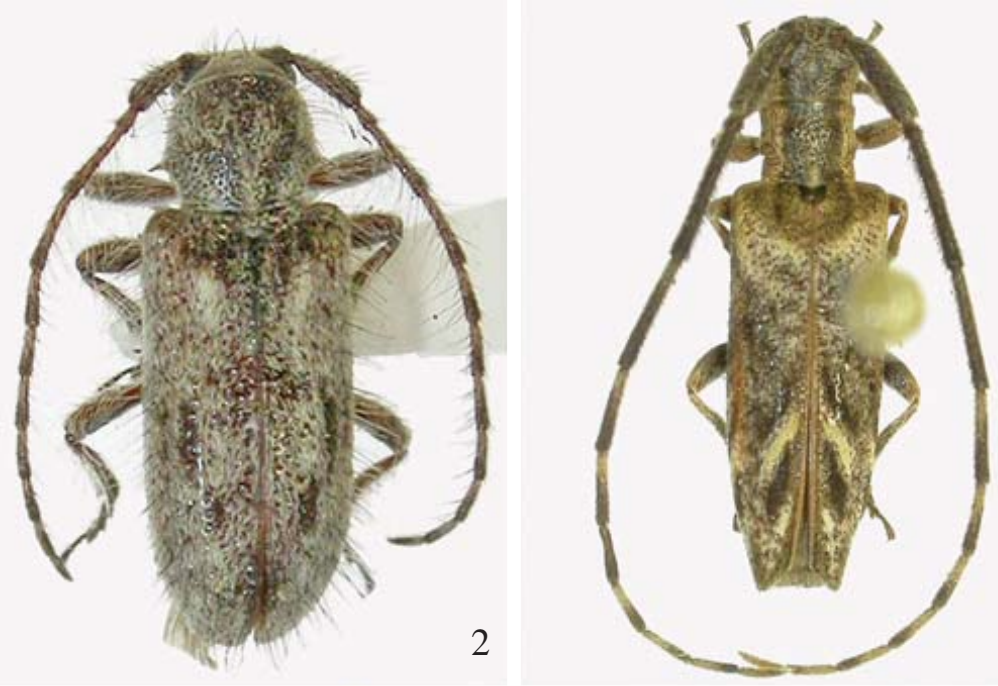

3

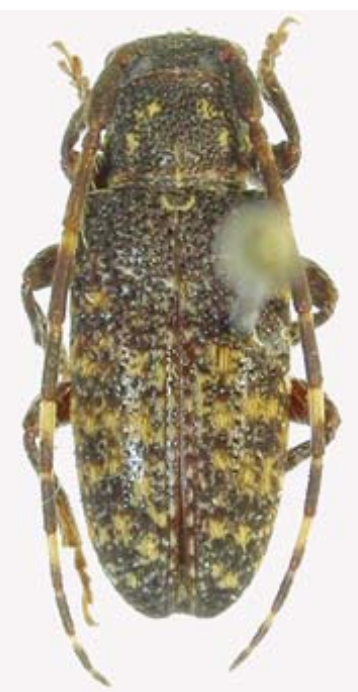

5

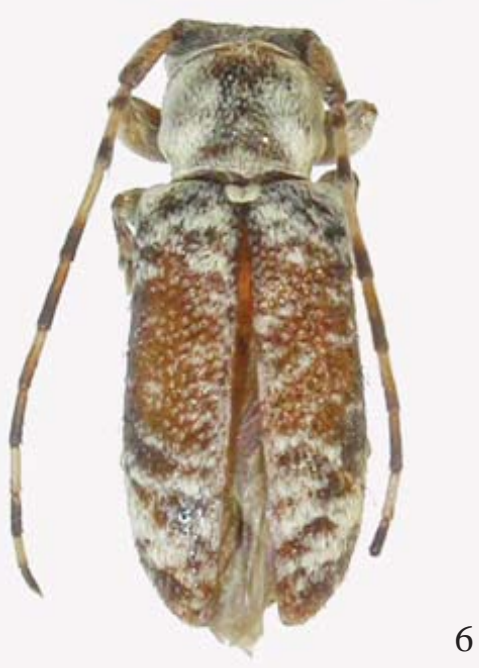

Figs. 1-6. Habitus: 1, Cotyschnolea minuta sp. nov., holótipo fêmea, comprimento 4,8 mm; 2, Mimasyngenes murutinga sp. nov., holótipo fêmea, comprimento 4,9 mm; 3, Stereomerus hovorei sp. nov., holótipo fêmea, comprimento 8,1 mm; 4, Estola medionigra Breuning 1940, exemplar MCNZ, comprimento 6,9 mm; 5, Estola timbauba sp. nov., holótipo fêmea, comprimento 7,8 mm; 6, Inermestoloides rumuara sp. nov., holótipo macho, comprimento $5,2 \mathrm{~mm}$.

todos os artículos; ultrapassam o ápice dos élitros a partir do antenômero VII. Escapo mais curto que o antenômero III. Antenômero III tão longo quanto o IV.

Protórax mais largo do que longo com espinho lateral. Lados do protórax com faixa de pubescência amarelada que recobre os espinhos laterais e os lados do pronoto; centro pontuado, exceto em pequena área lisa à frente do escutelo e revestida por pubescência amarelada. Escutelo com pubescência castanha. Metasterno com pubescência amarelada e pontos contrastantes.

Cada élitro com o quarto basal revestido por pubescência amarelada, seguida por área triangular de pubescência esbranquiçada; nos lados do terço central e no terço apical revestidos por pubescência acastanhada; quatro faixas de pubescência castanho-escura (mais visíveis quando o inseto está transversal à fonte luminosa), oblíquas em sentido descendente da sutura para a margem, duas dorsais próximas à sutura e duas laterais, soldadas ao friso marginal; entre aquelas duas primeiras, faixa oblíqua com pubescência amarelada; quinto apical com pequena faixa de pubescência branca internamente e atrás da faixa dorsal posterior. Extremidades elitrais fortemente oblíquas e aguçadas no ângulo externo.

Profêmures com pubescência amarelada e pontos contrastantes. Mesofêmures com a região central de tegumento preto e a metade apical coberta por pubescência amarelada e pontos contrastantes. Metafêmures com a região apical amarelada e grande parte basal com tegumento preto. Tíbias amareladas com extremidades pretas.

Urosternitos com pubescência amarelada e pontos contrastantes.

Dimensões em mm, holótipo fêmea. Comprimento total, 8,1; comprimento do protórax, 1,2; maior largura do protórax, 1,5; comprimento dos élitros, 5,8; largura umeral, 2,2. 
Material-tipo. Holótipo fêmea, EQUADOR, Manabi: Montecristi ("vicinity"), 9-10.III.2003, F. Hovore col. (FTHC).

Discussão. Stereomerus hovorei $\mathbf{s p . ~ n o v . ~ c a r a c t e r i z a - s e ~ p e l o ~}$ padrão de colorido e pelo ápice dos élitros fortemente oblíquo com projeção aguda no lado externo. Na chave para as espécies do gênero de Martins \& Galileo (1994), as espécies com fronte retangular apresentam faixas longitudinais de pubescência clara nos élitros o que não ocorre em S. hovorei sp. nov.

Etimologia. O nome da espécie é uma homenagem ao coletor e colecionador Frank T. Hovore (FTHC).

\section{Estola medionigra Breuning, 1940} (Fig. 4)

Estola medionigra Breuning, 1940: 66; Monné, 2005: 399 (cat.).

Tegumento corporal castanho-avermelhado. Fronte pontuada, revestida por pubescência amarelada. Região entre os lobos superiores dos olhos com pontos grandes. Lobos oculares superiores com sete fileiras de omatídios e tão distantes entre si quanto a largura de um lobo. Escapo com tegumento avermelhado, recoberto por pubescência amarelada. Antenômero III todo preto ou com anel basal amarelado; antenômeros IV-VII e IX-XI acastanhados com a base amarelada; antenômero VIII branco-amarelado com a ponta preta.

Espinho nos lados do protórax inconspícuo, apenas projetado. Pronoto inteiramente pubescente de amarelado ou com larga área central glabra e lados cobertos por pubescência amarelada; pontos contrastantes nos lados do pronoto e do protórax. Escutelo recoberto por pubescência amarelada. Lados do metasterno sem pontos.

Cada élitro com área umeral de pubescência amarelada que se inicia no escutelo, estende-se obliquamente para a margem até o quarto anterior; terço apical recoberto por pubescência amarelada; região central predominantemente castanha com manchas pequenas de pubescência amarelada. Pontos da mancha umeral contrastantes.

Pernas ou unicolores e pretas ou fêmures com tegumento castanho-avermelhado e tíbias acastanhadas com dois anéis de tegumento amarelado. Metatíbias dos machos com fóvea ovalar em todo o terço central da face dorsal, entre os anéis de tegumento amarelado; área interna da fóvea pubescente.

Urosternitos revestidos por pubescência amarelada.

Dimensões, em mm. Comprimento total, 6,9-8,1; comprimento do protórax, 1,5-1,8; maior largura do protórax, 1,7-2,2; comprimento do élitro, 4,8-5,7; largura umeral, 2,5-3,0.

Material examinado. GUIANA FRANCESA, Route de Kaw (km 7), macho, 28.II.1987, R. Larre col., armadilha luminosa (MNHN 0791); ditto (km 38), fêmea, 17.VIII.1993, J.-L. Giuglaris col., "battage" (MZSP); fêmea, 10.VIII.1996. O. Baloup col. "sur tronc, de nuit" (MNHN); ditto (km 45), macho, 29.XII.1986, O. Baloup col., armadilha luminosa (MCNZ); Roura (41 km SW, Kaw Rd, 432,214’ N, 5207,420’W, 272 m), fêmea, 8.XII.2002, J. E. Eger col. (CRML).
Discussão. Estola medionigra só era conhecida pelo holótipo procedente de Jataí, Goiás, Brasil e distingue-se das demais espécies do gênero pelo padrão de colorido dos élitros com mancha umeral de pubescência amarelada e pelas metatíbias com fóvea ovalar, internamente pubescente, que ocupa o terço central da face dorsal.

\section{Estola timbauba sp. nov.}

(Fig. 5)

Tegumento corporal preto, mais avermelhado nas pernas; tarsômeros III-V com tegumento alaranjado. Cabeça com pubescência amarelada, muito esparsa; no meio da fronte, dois pincéis de pêlos brancos. Antenas com tegumento castanho, base dos antenômeros III-V, VII, IX e XI amarelada; antenômeros VI, VIII e X com a metade basal amarelada.

Espinho lateral do protórax manifesto. Pronoto forte e densamente pontuado; praticamente glabro, com cinco pincéis de pêlos branco-amarelados: dois mais próximos entre si, no nível do terço anterior, dois mais afastados entre si no nível do terço posterior e um à frente do escutelo. Partes laterais do protórax com pequena mancha de pubescência brancoamarelada à frente do espinho. Mesepimeros pontuados. Lados do metasterno liso.

Élitros com o terço anterior provido de pubescência muito esparsa, praticamente glabro; restante da superfície com manchas irregulares, pequenas, de pubescência amarelada; extremidades ocupadas por área preta.

Fêmures, tíbias e face ventral do corpo, castanhoavermelhados, pubescentes.

Dimensões, em mm, holótipo fêmea. Comprimento total, 7,8; comprimento do protórax, 1,6; maior largura do protórax, 2,1; comprimento do élitro, 5,9; largura umeral, 2,7.

Material-tipo. Holótipo fêmea, BOLÍVIA, Santa Cruz: Buena Vista (Hotel Flora \& Fauna, 4-6 km SSE), 27-29.X.2000, Wappes \& Morris col. (MNKM).

Discussão. Duas espécies descritas da Bolívia, Estola fuscomarmorata Breuning, 1940 e Estola boliviana Breuning, 1940 apresentam colorido semelhante ao de Estola timbauba sp.nov.

Difere de E. fuscomarmorata pelo antenômero $\mathrm{V}$ com anel basal amarelado, pelo pronoto esparsamente pubescente e somente com 5 máculas de pubescência amarelada; pelo terço anterior dos élitros sem mancha amarelada. Em E. fuscomarmorata, examinada através de fotografia do holótipo depositado no National Museum of Natural History, Washington, o antenômero $\mathrm{V}$ é inteiramente preto, o pronoto é revestido por pubescência amarelada e os élitros apresentam grande mancha umeral de pubescência amarelada que se estende até quase o meio e mancha semelhante nos lados do terço apical.

Separa-se de Estola boliviana pelo antenômero VI com a metade basal amarelada e pela ponta dos élitros com mancha preta; em E. boliviana, o antenômero VI apresenta apenas o anel basal amarelado e a ponta dos élitros não tem mancha preta. 
Etimologia. Tupi, timbauba = nome da "árvore da espuma" que é uma Leguminosae.

\section{Inermestoloides rumuara sp. nov.} (Fig. 6)

Tegumento castanho-avermelhado exceto élitros e antenas. Fronte acentuadamente transversal, pontuada e com pubescência amarelada esparsa; no meio da parte superior com mácula de pubescência branca. Genas e regiões laterais da cabeça com pilosidade branca e densa. Antenas apenas alcançam o ápice elitral a partir da metade do XI. Escapo cilíndrico com tegumento avermelhado menos no ápice que é preto; pilosidade esparsa e esbranquiçada. Flagelômeros escuros; antenômeros III-VII, IX com anel apical de tegumento avermelhado gradualmente mais estreito em direção aos apicais; antenômeros VIII e X inteiramente brancos; antenômero XI preto.

Protórax com a constrição basal mais acentuada que a anterior; lados com gibosidade no nível do terço posterior. Pronoto glabro no centro, com pubescência branca e densa nos lados. Mesepimeros com pubescência branca e densa, restante da face ventral do corpo com pubescência branca e esparsa.

Quarto anterior dos élitros e terço apical (menos os ápices) com pubescência branca em manchas irregulares mais ou menos transversais; região central quase sem pilosidade exceto pubescência branca, esparsa, ao longo da sutura. Extremidades arredondadas. Setas elitrais curvas com ápice rombo.

Pernas avermelhadas; meso- e metatíbias com dois anéis de tegumento alaranjado.

Dimensões, em mm, holótipo macho/parátipo fêmea. Comprimento total, 5,2/5,5 comprimento do protórax, 1,1/1,4; maior largura do protórax 1,2/1,5 comprimento do élitro 3,7/4,1; largura umeral, 1,9/1,8.

Material-tipo. Holótipo macho, BOLÍVIA, Santa Cruz: Buena Vista

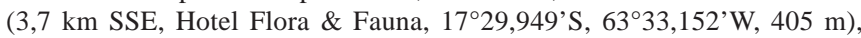

5-15.XI.2001, M. C. Tomas \& B. K. Dozier col. "tropical transition forest" (FSCA). Parátipo fêmea, mesmos dados do holótipo (MZSP).

Discussão. Até o momento o gênero Inermestoloides Breuning, 1966 estava representado por única espécie $I$. preapicealba Breuning, 1966 que tem padrão de colorido diferente, a pubescência branca dos élitros está restrita à parte lateral da metade posterior. Em Inermestoloides rumuara $\mathbf{s p .}$ nov., a pubescência branca nos élitros reveste o quarto anterior e terço apical (menos os ápices).

Etimologia. Tupi, rumuára = companheiro, companheira; alusivo a constituir-se a segunda espécie do gênero.

Agradecimentos. Aos responsáveis pelas coleções, Frank T. Hovore (FTHC), M. C. Thomas (FSCA), Gérard Tavakilián (MNHN), Roy Morris (CRML) pelo envio de material para estudo. A Rafael Santos de Araujo (MCNZ) pela execução das fotografias.

\section{REFERÊNCIAS}

Breuning, S. 1940. Novae species Cerambycidarum. VIII. Folia Zoologica Hydrobiologica 10: 37-85.

Breuning, S. 1974. Révision des Rhodopinini américains. Studia Entomologica 17: 1-210.

Galileo, M. H. M. \& U. R. Martins. 1996. Notas e descrições em Desmiphorini (Coleoptera, Cerambycidae, Lamiinae), com uma revisão do gênero Mimasyngenes Breuning. Revista Brasileira de Zoologia 13: 867-882.

Martins, U. R. \& M. H. M. Galileo. 1994. Revisão do gênero Stereomerus Melzer, 1934 (Coleoptera, Cerambycidae,Lamiinae, Desmiphorini) Papéis Avulsos de Zoologia 39: 1-11.

Martins, U. R. \& M. H. M. Galileo. 1998. Gêneros sul-americanos de Desmiphorini (Coleoptera, Cerambycidae) com lados do protórax desarmados. Revista Brasileira de Entomologia 41: 257-265.

Monné, M. A. 2005. Catalogue of the Cerambycidae (Coleoptera) of the Neotropical region. Part II. Subfamily Lamiinae. Zootaxa 1023 $1-760$.

Recebido em 21/02/2006; aceito em 10/09/2006 